\title{
A CASA DE SEMENTES MÃE ZENILDA E O FORTALECIMENTO DA AGRICULTURA ANCESTRAL XUKURU
}

\section{THE HOUSE OF MOTHER ZENILDA SEEDS AND THE STRENGTHENING OF ANCESTRAL AGRICULTURE XUKURU}

\author{
Marli Gondim de Araújo \\ Doutoranda do Programa de Pós Graduação em Geografia da Universidade Federal de Pernambuco \\ marligondim@gmail.com
}

Iran Neves Ordônio

Agrônomo do Coletivo de Agricultura Xukuru Jupago Kreká iranxukuru@gmail.com

\section{Resumo}

Os indígenas Xukuru vivem na Serra do Ororubá, municípios de Pesqueira e Poção, no agreste pernambucano. Segundo relatos de lideranças Xukuru, especialmente do Cacique Xikão, assassinado em 1998 pelos fazendeiros, Xukuru é nome de pássaro da mata; ororubá vem da árvore ubá e/ou ororubá. A junção dos dois nomes formou Xukuru do Ororubá, que significa o respeito do índio pela natureza. Os registros de contato com os colonizadores datam do século XVI, tendo no século XIX, os antepassados Xukuru recebido as terras por sua participação da Guerra do Paraguai. Desde então se sucederam lutas e conflitos entre Xukuru e invasores de suas terras, fazendeiros de gado (SILVA, 2008). Após muitas pelejas, os Xukuru sob a liderança de Xikão, iniciaram uma série de retomadas de seu território em fins da década de 1980 , para só em 2001 conseguirem a titulação e demarcação definitiva.

Palavras-chave: Casa de Sementes. Mãe Zenilda. Agricultura Familiar. Xukuru. Orubá.

\begin{abstract}
The Xukuru indigenous people live in the Serra do Ororubá, municipalities of Pesqueira and Poção, in the rough of Pernambuco. According to reports by Xukuru leaders, especially Cacique Xikão, murdered in 1998 by farmers, Xukuru is the name of a bird of the forest; ororubá comes from the ubá and / or ororubá tree. The combination of the two names formed Xukuru do Ororubá, which means the Indian's respect for nature. The records of contact with the colonizers date from the 16th century, with the Xukuru ancestors receiving the lands in the 19th century for their participation in the Paraguayan War. Since then, there have been struggles and conflicts between Xukuru and invaders of their lands, cattle ranchers (SILVA, 2008). After many struggles, the Xukuru, under the leadership of Xikão, started a series of retakes of their territory in the late 1980 s, only in 2001 to achieve the title and definitive demarcation.
\end{abstract}

Keywords: Seed House. Mother Zenilda. Family farming. Xukuru. Orubá. 


\section{Introdução}

Os indígenas Xukuru vivem na Serra do Ororubá, municípios de Pesqueira e Poção, no agreste pernambucano. Segundo relatos de lideranças Xukuru, especialmente do Cacique Xikão, assassinado em 1998 pelos fazendeiros, Xukuru é nome de pássaro da mata; ororubá vem da árvore ubá e/ou ororubá. A junção dos dois nomes formou Xukuru do Ororubá, que significa o respeito do índio pela natureza. Os registros de contato com os colonizadores datam do século XVI, tendo no século XIX, os antepassados Xukuru recebido as terras por sua participação da Guerra do Paraguai. Desde então se sucederam lutas e conflitos entre Xukuru e invasores de suas terras, fazendeiros de gado (SILVA, 2008). Após muitas pelejas, os Xukuru sob a liderança de Xikão, iniciaram uma série de retomadas de seu território em fins da década de 1980, para só em 2001 conseguirem a titulação e demarcação definitiva.

As lutas dos Xukuru em defesa do seu território e de sua cultura, assim como várias nações indígenas no Brasil, datam da época da colonização. Como bem afirmou o Cacique Xikão no vídeo dedicado ao grande líder indígena, Xicão Xucuru, (2003): “A destruição do nosso povo não é de agora, ela já vem de muito tempo. São quinhentos anos de luta e opressão.”. A invasão do território brasileiro pelos europeus, consistiu num processo colonizador de expropriação dos indígenas de suas terras originárias e uma tentativa de supressão da cultura, representada pela religião (cultos, ritos, símbolos), comidas, indumentárias, enfeites e na relação mantida com a natureza, entre outros atributos. A colonialidade deixou marcas profundas, inclusive na construção dos conhecimentos.

(...) la construcción de conocimientos y prácticas "otros", a partir de la
identificación de los elementos de la matriz colonial como la colonialidad del
saber, del poder, y otros, y sus relaciones. En todas estas normatividades se
ha encontrado el carácter invisibilizador de los indígenas y sus
conocimientos; centrándose este discurso simbólico del poder oficial en la
tácita suplantación de la identidad indígena por la matriz civilizadora, con sus
atributos de evangelizador, civilizador, modernizador, progresista,
desarrollista y globalizador. (MENDOZA, 2010)

Os colonizadores impuseram sua cultura em substituição à cultura original indígena, com valores mercantis e cristãos, ameaçando a relação de cooperação que os indígenas desenvolviam com a natureza, explorando e saqueando os bens comuns numa tentativa de invisibilização da cultura indígena. Foram séculos de opressão, que 
influenciaram e provocaram mudanças na identidade dos povos originários. Em contraponto, houve e ainda há, muita resistência. Uma delas, já anunciada, se configura na proteção aos bens comuns da natureza e na forma como se dá a produção de alimentos.

Para os indígenas, a natureza é sagrada, o que se coaduna com a manutenção dos bens comuns - os quais não são de usufruto exclusivo dos indígenas - o que tem sido garantido em grande medida por esses povos. E é graças a essa compreensão, traduzida em vivências práticas, que grande parte dos bens comuns naturais localizados em territórios indígenas, encontram-se preservados. Por isso, os indígenas são considerados guardiões da natureza.

Há vários exemplos sobre isso. Vejamos, um estudo conduzido pelo Instituto de Pesquisa Ambiental da Amazônia (IPAM), concluiu que no período de 2000 a 2014, a perda da vegetação dentro das terras indígenas na Amazônia, foi de apenas 2\%, ao passo que a média de área desmatada em toda a floresta no mesmo período foi de 19\%. Face a esta constatação é possível afirmar que os territórios indígenas têm contribuído para o equilíbrio do clima. (VICK, 2019).

As iniciativas de proteção aos bens comuns e de produção nos moldes da agricultura tradicional e ancestral são várias. A constituição da Casa de Sementes e Centro de Formação da Agricultura Tradicional Mãe Zenilda se constitui numa iniciativa recente e ousada para os indígenas Xukuru. Localizada na Aldeia Couro Dantas, o espaço político-pedagógico, visa dar continuidade aos processos formativos quanto à agricultura tradicional Xukuru, ao Sistema de Cura Tradicional e às atividades de produção de artesanato desenvolvida por mulheres e homens no território indígena.

É essa história de lutas e iniciativas como a Casa de Sementes Mãe Zenida, que dão significado e protagonismo aos indígenas Xukuru do Ororubá enquanto defensores do seu território, das sementes tradicionais e da natureza sagrada.

\section{Localizando o território Xukuru}

A Serra do Ororubá localiza-se no município de Pesqueira, agreste pernambucano. É lá que vivem cerca de 12.500 indígenas distribuídos em 24 aldeias. Há ainda cerca de 200 indígenas que moram no bairro "Xucurus" em Pesqueira. São 27.555 hectares de terra demarcada, com três sub-regiões geográficas distintas: Serra, 
Agreste e Ribeira. (Figura 1 e 2). Destaque-se que essa sub-regionalização é devida, muito provavelmente, à leitura das características ambientais do território realizada pelos indígenas. Note-se no Mapa 1, a localização do território em relação ao Planalto da Borborema.

Figura 1: Mapa de localização do Território indígena Xukuru. Organizado por Marli Gondim em conjunto com MapGeo, 2021.

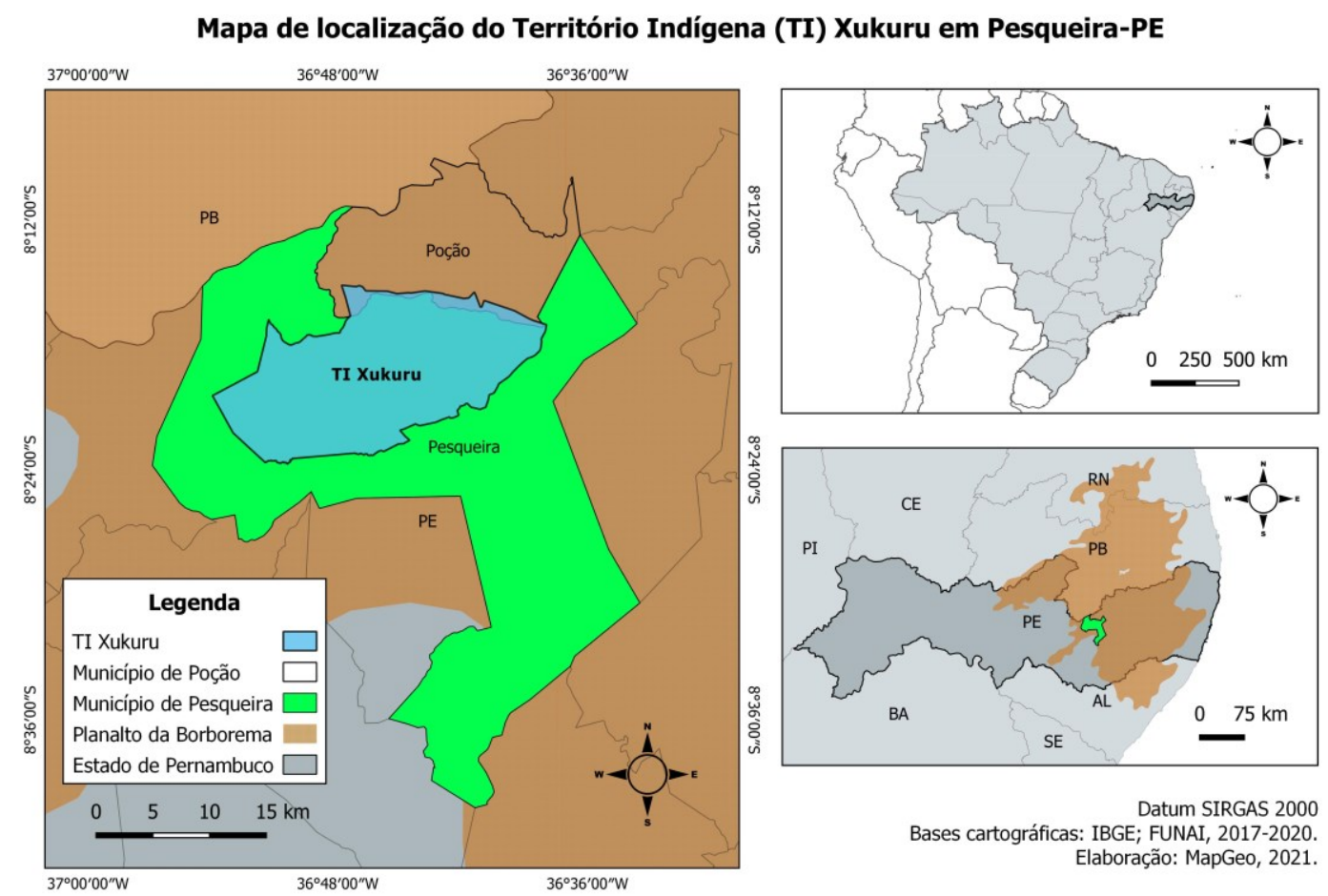


Figura 2: Mapa com as divisões e as 24 aldeias. Na cor amarela, Sub-região Agreste; na cor azul, Sub-região Ribeira; na cor verde, sub-região Serra. Organizado por Marli Gondim em conjunto com MapGeo, 2021.

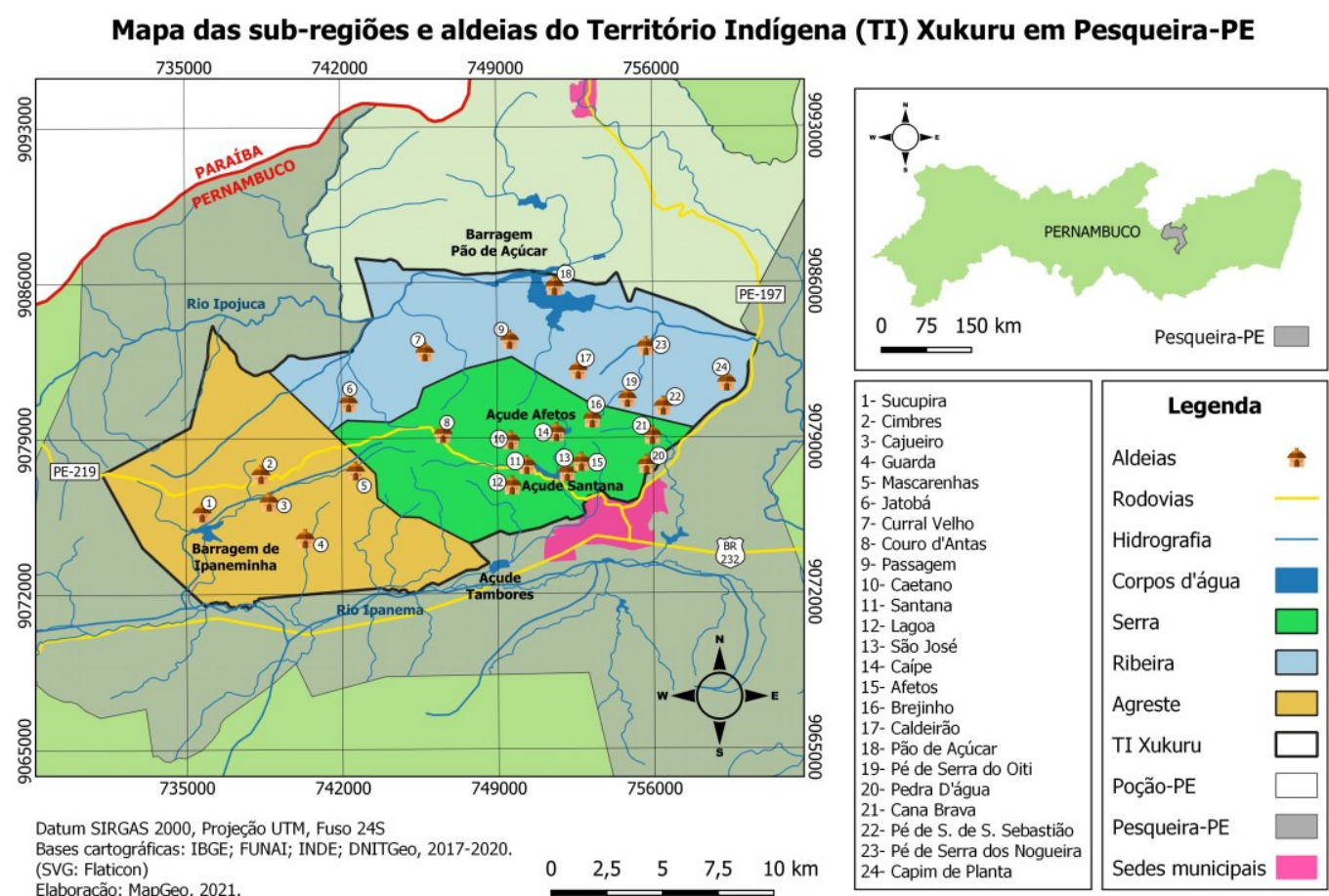

Vejamos o que diz Barbalho (1977 p. 45, apud SILVA, 2011), sobre a Serra do Ororubá:

Toda aquela região do fim do Agreste e começo do Sertão de Pernambuco, era ocupada pelos indígenas que a habitavam, era taxada de Borborema, o que no dialeto deles, queria dizer deserto. Em pleno "deserto", contudo, sobressaía-se um Oasis - a gigantesca serra do Urubá, onde o clima era ameno e salutar, a terra forte e fecunda. Por seus rios, córregos e riachos, corria abundante água potável, havia fertilidade perene, e constituía verdadeiro contraste naquele sertão árido e seco. O Urubá era mesmo o Oasis da Borborema, pitoresco recanto dentro de cujos limites viviam, primitivamente, índios tapuios da tribo dos Arorobas, nome pelo qual, logo ficaria popularizada a serra. (SILVA, 2011).

E foi muito provavelmente o fato de ser um "oásis", de gozar de fertilidade perene, que a Serra do Ororubá, tornou-se lugar de cobiça para grileiros, fazendeiros e demais grupos de poderosos que às custas da conivência dos Governos locais e cartórios, se apossaram e grilaram as terras dos Xukuru. 


\section{As retomadas dos territórios originários Xukuru}

As lutas desenvolvidas pelos Xukuru, ao longo sobretudo da segunda metade do século $\mathrm{XX}$, pela reconquista de suas terras originárias, teve seu ápice no bojo das discussões para a construção da Constituição de 1988, na qual os indígenas tiveram um papel fundamental na garantia de seus direitos.

$\mathrm{Na}$ verdade, desde os processos de colonização, no século XVI, que os povos originários travam lutas pelo reconhecimento e direito à terra. Com os Xukuru não foi diferente, tendo suas lutas por retomada se intensificado em fins da década de 1980, quando teve início o processo de demarcação, como atesta levantamento de informações organizado por Fialho, Neves e Figueiroa: “Apesar de insistentemente reivindicada pelos Xukuru, as primeiras providências sobre a demarcação das terras desses índios só ocorreram recentemente, no final da década de 80." (FIALHO; NEVES; FIGUEIROA, 2011, p. 18-19).

A morosidade do Estado em demarcar o território Xukuru resultou na denúncia por parte dos indígenas assessorados pelo Conselho Indigenista Missionário (CIMI), em parceria com as Organizações Não Governamentais, Justiça Global e Gabinete de Assessoria Jurídica às Organizações Populares (GAJOP), à Corte Interamericana de Direitos Humanos (CIDH). Numa decisão histórica, em março de 2018,

(...) a Corte Interamericana de Direitos Humanos reconheceu a responsabilidade internacional do Estado brasileiro na violação aos Direitos de propriedade coletiva, garantia judicial de um prazo razoável e proteção judicial em relação ao povo indígena Xukuru de Ororubá. O país foi condenado a finalizar o processo de demarcação do território tradicional, localizado no município de Pesqueira, em Pernambuco. (...). No relatório de mérito do caso, divulgado em julho de 2015, a CIDH concluiu que o Estado brasileiro era responsável pelas violações de direitos do povo indígena Xukuru e fez recomendações ao Estado brasileiro, que não foram cumpridas até hoje. (EL PAÍS, 2018)

Mesmo reconhecendo essa recente e potente vitória, que ainda não foi de todo concluída, não se pode esquecer das lutas pela retomada do território, como um marco importante para os Xukuru. Cada uma das retomadas teve um movente específico de luta.

A primeira retomada ocorreu em 1990 na aldeia Pedra D’água. Liderados por Xikão e conduzidos pela Luz e Força Encantada dos trabalhos espirituais do Pajé 
Zequinha, os Xukuru reocuparam o espaço Sagrado da Pedra do Mestre Rei do Ororubá, do Terreiro Mãe da Pedra D’água e da área de Mata, morada encantada, para evitar o avanço da agricultura e pecuária realizadas por posseiros e invasores não indígenas. Essa conquista foi marcada pela retomada dos espaços sagrados, com a necessidade dos indígenas da realização de seus rituais, destacando o Toré, recuperando o espaço físico e o significado simbólico dos Terreiros sagrados.

A segunda retomada, em 1992, ocorreu num contexto de muitas perdas de vidas. Foram 29 crianças que morreram na Aldeia Caípe. Essa retomada ficou conhecida como a retomada pelo direito ao cultivo, pelo direito à agricultura.

Nas outras retomadas, “(...) foram ocupadas as fazendas, pois o que se buscava era garantir os meios de subsistência para o nosso povo e fortalecer a nossa identidade." (ALMEIDA; MARIN, 2012, p.9)

Com o espaço sagrado ocupado, o povo e sua organização social montaram estratégias de retomadas das suas terras, ao mesmo tempo em que reestruturam sua organização sociopolítica e elaboraram os acordos coletivos de uso e ocupação territorial baseados na manutenção da relação de fidelidade ao mundo dos encantados.

\section{A agricultura indígena Xukuru}

A agricultura indígena e a relação estabelecida com a natureza pelos povos originários, podem ser caracterizadas inicialmente pelo prodigioso conhecimento do ambiente natural por parte desses povos. Além disso, é sempre presente na literatura, que os indígenas incansavelmente, estudam e pesquisam - observam e classificam plantas e animais necessários à sua existência (RIBEIRO, 1987). Até os dias de hoje, os indígenas seguem manejando o ambiente natural de forma a preservar grande parte da biodiversidade que o caracteriza.

A atividade da agricultura tradicional Xukuru que, com as terras sob a tutela dos fazendeiros e grileiros, estava impedida de ser praticada livremente pelos indígenas, após a retomada do território, pode finalmente se estabelecer. Assim, após alguns poucos anos de território livre e demarcado, os agricultores indígenas deram início a um 
processo de retomada ${ }^{1}$ da agricultura tradicional dos ancestrais. Uma agricultura que, inspirada no mundo velho dos antigos, se assemelha à agricultura de base ecológica ou agroecologia, muito embora os Xukuru prefiram a denominação simples de agricultura tradicional indígena para o que vêm desenvolvendo no território.

Após a reconquista territorial e diante do desafio de garantir os ideais de Xikão e de outros guerreiros e guerreiras que tombaram na luta pela retomada da terra sagrada, os Xukuru passaram a discutir coletivamente estratégias de uso territorial de forma a não replicar os modelos de exploração da terra feitos pelos invasores que deixaram como herança grande parte do território e seus recursos naturais degradados. Dessa forma surge a partir de 2004 um grupo de indígenas - posteriormente denominado de Coletivo Jupago Kreká, para se inserir no modelo sociopolítico Xukuru - com o fim apoiar as lideranças na gestão territorial e ambiental. O Jupago Kreká é reconhecido internamente como movimento da agricultura indígena Xukuru e defende a ideia de agricultura modo de vida, princípio da organização social, além de elemento de identidade étnica e expressão cultural.

Agricultura, portanto, está imbricada em suas ações cotidianas, no "ser Xukuru", é questão identitária. As estratégias desenvolvidas pelos indígenas após a conquista e posterior regularização do território, para fortalecer a sua cultura e, particularmente, as atividades da agricultura ancestral, se configuram em várias frentes: 1. As atividades de produção agrícola, fundamentadas na agricultura tradicional ancestral ou de base ecológica; 2. A realização de atividades de formação, de troca de experiências e de partilha de sementes tradicionais do território indígena, através da realização de eventos anuais; 3. As atividades de discussão, formação e deliberação política estratégica - a exemplo da Assembleia Anual Xukuru; 4. Constituição da Casa de Sementes Mãe Zenilda.

As atividades de produção da agricultura tradicional, se configuram em espaços distribuídos em várias aldeias nas três sub-regiões, mas sobretudo na região da Serra. (Fotos 1 e 2)

\footnotetext{
${ }^{1}$ A ideia de "retomada" remete ao processo de reconquista física e política do território, sendo por associação empregada aqui na reconstrução de outros elementos da identidade indígena, como agricultura e espiritualidade.
} 
Foto 1: Hortas na Aldeia Santana, Região da Serra, 2011. Acervo da autora.

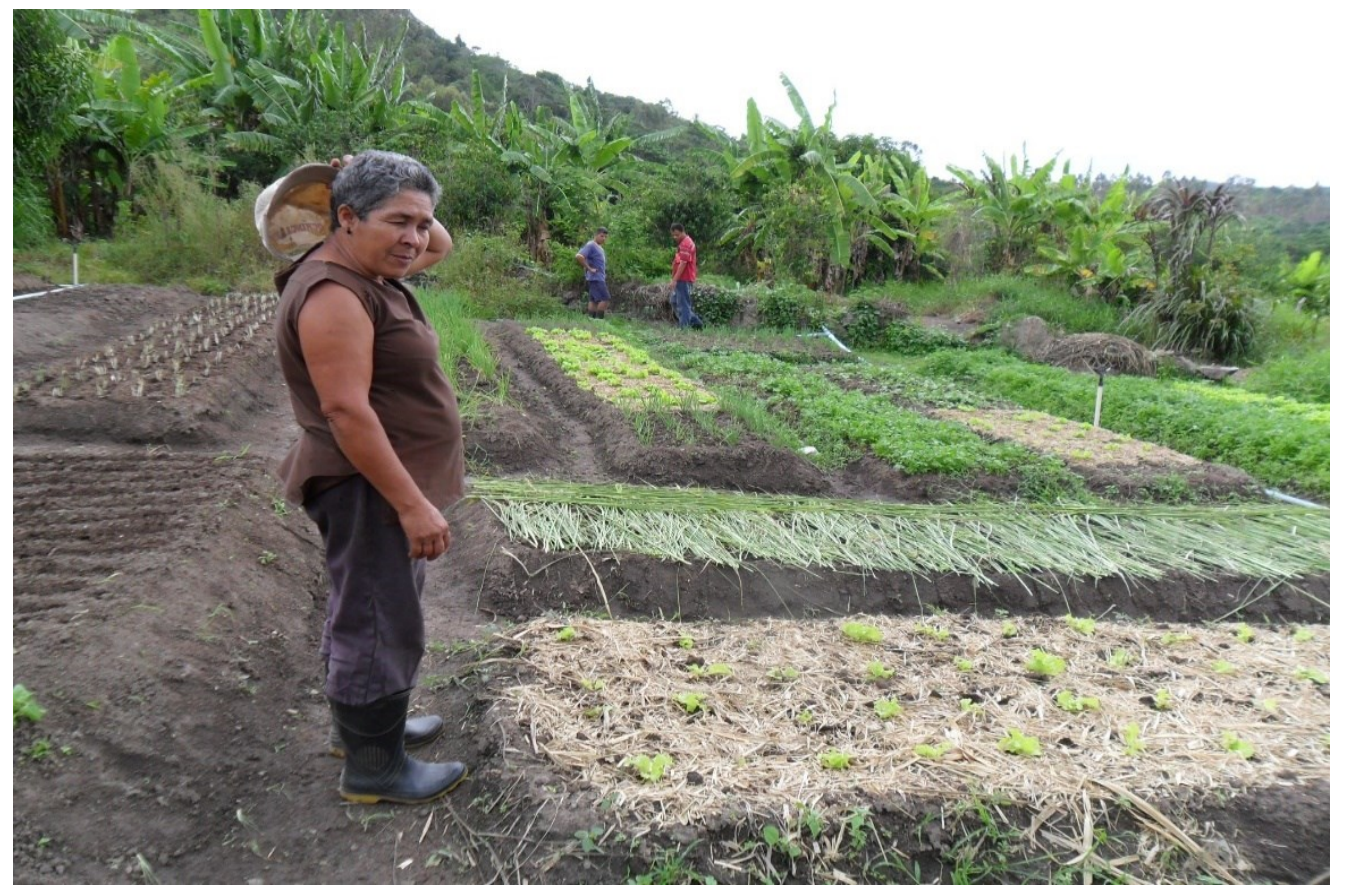

Foto 2: Mutirão para construção de mandala, Espaço CAXO, Aldeia da Boa Vista, Subregião da Serra, 2019.

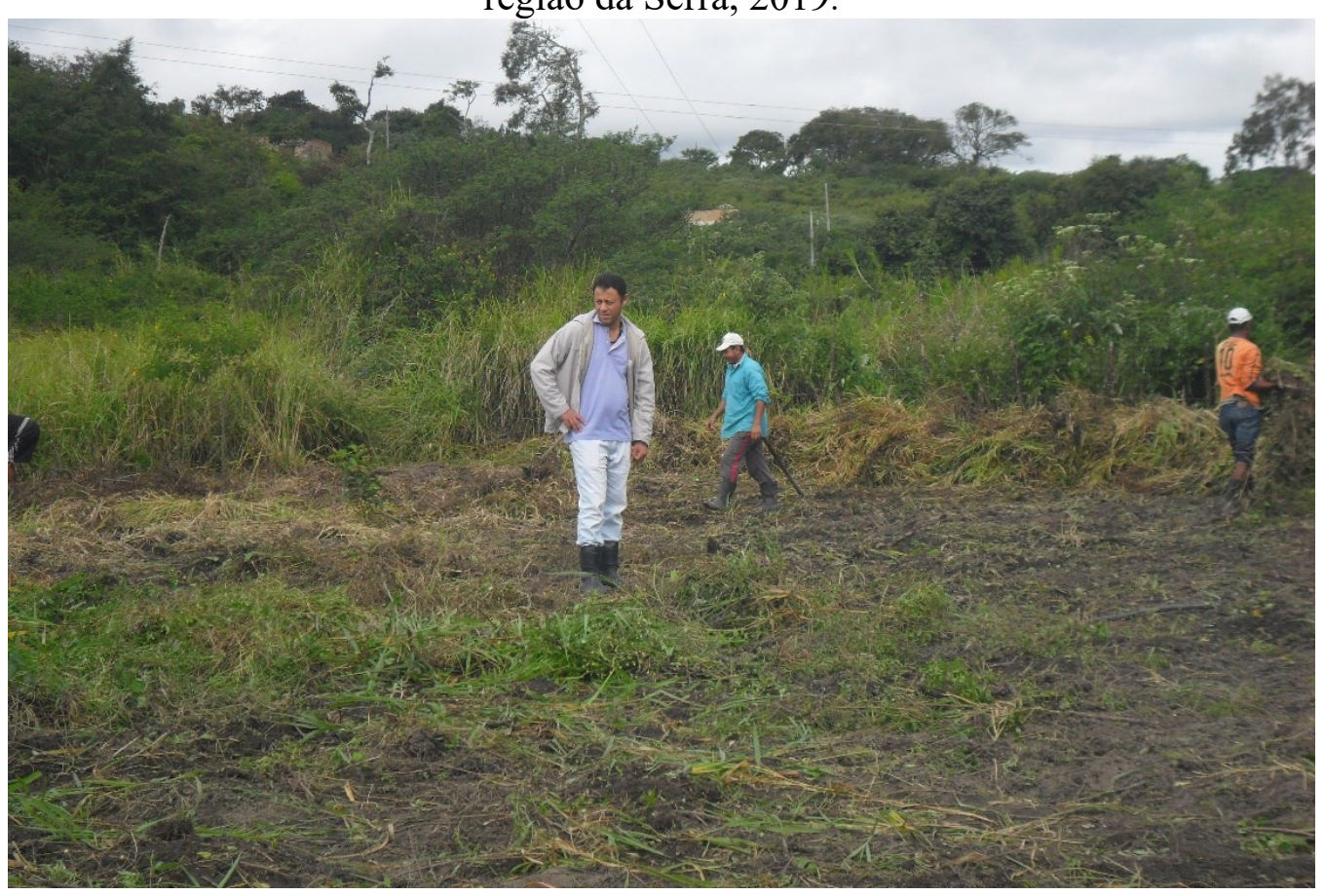

Fonte; Acervo da autora.

A produção de hortaliças, frutas, tubérculos, entre outros, já acontece desde 2000, culminando com a instalação em 2006 do espaço de comercialização dos Xukuru 
na feira de Pesqueira aos sábados, que também funciona às quartas feiras. Atualmente também comercializam no município de Arcoverde, às sextas feiras. Os cultivos são feitos de acordo com os princípios da agricultura tradicional ancestral - de base ecológica - mas também de acordo com as orientações dos "encantados" - os que não estando nesse plano físico, "orientam" e inspiram os indígenas a desenvolverem a agricultura ancestral. Uma produção identificada com os princípios da agroecologia, sem uso de agrotóxicos ou de fertilizantes químicos. São 20 famílias que comercializam seus produtos nas feiras.

Mas para chegar até aí os Xukuru desenvolveram várias ações estratégicas. A parceria entre Instituto Agronômico de Pernambuco (IPA), Jupago Kreká (Coletivo de Agricultura indígena no território) e a associação da comunidade indígena Xukuru, formaram a rede de ATER indígena, ferramenta importante e sistêmica, para promover e articular trabalhos de extensão rural no território Xukuru de forma a somar esforços para a construção coletiva do projeto de vida, Lymolaygo Toype - Terra dos Ancestrais, tradução para o Bem Viver Xukuru do Ororubá.

1. Uma segunda estratégia, se constitui na realização de eventos específicos anuais dedicados à agricultura: leitura dos sinais do tempo e da natureza, partilha de sementes tradicionais e intercâmbio de conhecimentos.

A construção de um calendário da agricultura e de uma agenda coletiva do Jupago resultaram na realização de eventos anuais que buscam promover a reflexão, o planejamento e o intercâmbio de práticas e saberes sobre a agricultura tradicional Xukuru. Nesse calendário destacamos o Encontro de Sábios e Sábias da Natureza Lonjy-abaré, onde se reúnem os mais velhos, jovens, mulheres para socializar as experiências de leituras dos sinais da natureza, interpretação e previsão da chegada de chuvas no território ${ }^{2}$. É realizado no último domingo de janeiro, já que os agricultores devem iniciar o ano orientados por essas previsões para poderem planejar seu calendário agrícola.

\footnotetext{
2- As previsões populares do tempo e da "invernada" são comuns no Nordeste, fazendo parte da cultura camponesa. Nesse contexto, os indígenas apresentam uma série de observações e procedimentos peculiares.
} 
O Encontro Urubá Terra é realizado em novembro e reúne jovens, estudantes, agricultores, pesquisadores para juntos avaliarem e discutirem as estratégicas adotadas para as atividades agrícolas. É também um momento em que se presencia a "materialização do encantamento", expressão que simboliza a materialização dos desejos, do planejamento e da orientação dos encantados para a agricultura, ali expressas em sementes. A riqueza e diversidade das sementes ancestrais dos Xukuru são partilhadas com todos os indígenas das 3 sub-regiões geográficas. É graças a essa diversidade ambiental que são cultivadas as sementes de milho, feijão, fruteiras, roças, entre outras que dão sustento, junto a outras ações, à reprodução socioeconômica e cultural dos Xukuru.

Há uma prática ritual de plantio denominada Apresentação das Sementes, que ocorre dia 2 de fevereiro e consiste num ritual de oferta das sementes às entidades religiosas Xukuru para que a lavoura e o ano agrícola venham com fartura, livre de pragas e doenças. O plantio no dia 2 de fevereiro, ocorre independente do solo estar seco ou úmido.

Essa lógica em torno das sementes traz uma concepção com outros significados. Para os Xukuru o termo semente não se limita ao material genético, mas também a tudo que produz e reproduz conhecimento, luta e resistência.

É no Encontro de Sábios e Sábias e no Encontro Urubá Terra que percebemos a potência da produção agrícola dos indígenas e da guarda das sementes ancestrais. Sementes crioulas que foram guardadas ou reintroduzidas no território para serem multiplicadas, contribuindo com o aumento da biodiversidade e do patrimônio genético e identitário dos Xukuru do Ororubá.

Os Xukuru se consideram sementes de Mandarú, nome indígena de Xikão, pois lutaram pela liberdade da terra e de tudo que à terra pertence e hoje continuam a luta para garantir terra, liberdade e coletividade; para garantir o seu legado e o Bem Viver Xukuru, sendo assim fiéis à terra velha, mundo dos encantados. Xikão Xukuru foi semente e quando as condições passaram a ser favoráveis, o seu espírito guerreiro partiu, para a autoafirmação étnica, a união e organização em torno das conquistas dos direitos indígenas à terra, a um sistema de educação e saúde especifico e diferenciado, hoje garantidos na Constituição Federal de 1988. Dez anos depois, em maio de 1998, 
Xikão passou a ser semente novamente quando foi assassinado durante a luta pela direto a terra.

Essas sementes e seus cultivos garantem a crença de mundo fundada na cosmovisão de que o território físico material, chamado de natureza biológica, se comunica através das águas, das pedras e das árvores com a Natureza Sagrada, ou seja, o território espiritual Xukuru, o mundo dos reinados encantados.

2. O calendário anual de eventos dos Xukuru é formado por uma gama de atividades, cujos objetivos têm a ver as necessidades dos indígenas de realizarem a gestão democrática do território em suas várias áreas: agricultura Encontro de Sábios e Sábias (último domingo de janeiro), Cerimônia de Apresentação das Sementes (2 de fevereiro) e Encontro Urubá Terra (novembro); Festividades religiosas: Busca da Lenha (23/06) e Festa de Mãe Tamain (2 de julho); Educação, Saúde e estratégias políticas dos indígenas Assembleia Anual (17 a 20 de maio).

É nesses eventos que se juntam aos indígenas uma variada e diversa quantidade de parceiros e aliados dos indígenas: Universidades, Institutos Federais, estudantes de nível médio, pesquisadores/as, membros de movimentos de apoio às causas populares, religiosos/as, representantes de Organizações Não Governamentais, Comissão Indigenista Missionária (CIMI), representantes de veículos e comunicação, representantes de governos municipais e estadual, "parentes" de outras nações indígenas do país, a população envolvente de Pesqueira e outros municípios vizinhos, entre outros.

A Assembleia Xukuru, hoje com contornos de Assembleia Popular, como enfatizou o Professor Saulo Feitosa, em maio deste 2019, no entanto é onde se concentra o maior número de indígenas e parceiros, além de outros povos do estado de Pernambuco e de outros estados. A cada Assembleia, uma nova pauta de discussões e uma Carta assinada por todas as aldeias e parceiros é lançada.

A Carta da Assembleia realizada em 2019, traz o seguinte trecho

Quanto aos crimes ambientais, preservamos a certeza de que a Natureza Sagrada, em especial para os povos originários, é mãe e mantenedora da subsistência da vida. Ela necessita ser respeitada e cuidada com zelo por ser morada da Força Encantada que nos impele e impulsiona na luta. Rebatemos as medidas do poder público e privado que NÃO SÃO capazes de suprir as necessidades básicas das pessoas afetadas por estes crimes e nos unimos com força e coragem com aqueles que se lesam por tais ações omissas a realidade do povo, como a implantação da usina nuclear na cidade de Itacuruba - PE, 
que irá destruir o meio ambiente e mudar a estrutura cultural e social das pessoas. (Carta da 19a Assembleia Xukuru, 2019)

Um claro posicionamento em defesa da Natureza Sagrada, aliado a lutas alheias ao território Xukuru, mas que são parte das lutas populares contra a territorialização do capital, expresso em grandes obras, em detrimento das pessoas, do meio ambiente e da cultura local.

3. A Casa das Sementes Mãe Zenilda é um espaço recentemente construído no território indígena, na Aldeia Couro Dantas que vem funcionando como Centro de Formação em Agricultura Tradicional e assume uma importância fundamental nas estratégias de formação e de fortalecimento dessa agricultura ancestral. Foi instalada em um espaço coletivo denominado pelos Xukuru de Centro de Agricultura Xukuru do Ororubá (CAXO) da Boa Vista. Um dos objetivos do espaço é dar visibilidade ao conjunto de experiências em agricultura tradicional indígena Xukuru, promover os circuitos de práticas e saberes imersos nos sistemas tradicionais de cura, sistemas agroalimentares e agroflorestais, guarda de sementes, economia de reciprocidade e dinâmicas sociais de partilha e solidariedade.

Essa iniciativa se constitui num ousado e inovador movimento protagonizado pelos indígenas para aprofundar e dar visibilidade interna e externamente às diversas iniciativas de fortalecimento da cultura indígena, do que distingue e caracteriza a identidade indígena Xukuru. Com isso, os Xukuru darão mais musculatura às atividades de guarda das sementes e sua consequente multiplicação no território, mas também fortalecerão as redes de apoio aos indígenas constituídas pelas universidades, IPA, Institutos Federais (IFs), Organizações Não Governamentais (ONGs), setores dos governos estadual e municipal e até parceiros internacionais da causa indígena.

A Casa de Sementes já assume um papel importante nos processos formativos. No I Seminário da Educação do Campo e II Seminário de Agroecologia do Instituto Federal de Pernambuco (IFPE), campus Pesqueira, realizado no local no período de 5 a 7 de junho de 2019, foi lançada a Carta da Casa das Sementes, cujo conteúdo reafirma a importância da agricultura de base ecológica e dos encantados:

Acreditamos que a agroecologia, a agricultura do encantamento que respeita a terra e fortalece a soberania alimentar da população com a valorização de sua diversidade, possibilita aos povos do campo dignidade e respeito, sendo o 
caminho que deve ser trilhado por nosso país na busca de uma verdadeira alimentação. (CARTA DA CASA DE SEMENTES, 2019)

E é nesse sentido que os indígenas Xukuru defendem a guarda de suas sementes, como uma defesa de seu território, tão arduamente conquistado, à custa de muitas lutas e sofrimentos, cuja ênfase sempre foi pautada na defesa dos direitos dos Xukuru de viver, plantar e colher e na manutenção do território sagrado.

\section{À guisa de conclusão}

No contexto político atual extremamente desfavorável aos povos tradicionais, à sociedade civil organizada, à população pobre no Brasil, em que a supressão de direitos conquistados, os crimes contra o meio ambiente, contra a soberania nacional, assassinatos e ameaças sofridas pelas lideranças dos povos tradicionais, a liberação de centenas de agrotóxicos, em favor do agronegócio e contra a demarcação dos territórios indígenas, tornaram-se acontecimentos cotidianos, as lutas e estratégias de enfrentamento ao capital e às ações genocidas do governo brasileiro, desenvolvidas pelos povos originários e, particularmente pelos indígenas Xukuru, se constituem em iniciativas de fortalecimento e afirmação da cultura indígena e de defesa do território e dos bens comuns da Natureza Sagrada.

As estratégias de gestão territorial, fortalecimento da agricultura tradicional ancestral Xukuru e constituição da Casa de Sementes Mãe Zenilda, são fonte de inspiração e de resistência sólida e potente contra as artimanhas e garras do capital, do agronegócio e do latifúndio, que devem cada vez mais atrair e ajudar a sociedade de modo geral, mas particularmente os movimentos sociais do campo popular, no posicionamento contra os desmandos e ações de destruição da vida, aniquilação da identidade e da cultura, da diversidade, do meio ambiente e dos direitos conquistados ao longo das últimas três décadas.

\section{Referências}

ALMEIDA, Alfredo W. B. de; MARIN, Rosa E.A.(orgs); FIALHO et al. (equipe técnica). Nova Cartografia Social dos Povos e Comunidades Tradicionais do Brasil: Xukuru do Ororubá - PE. Manaus: UEA Edições, 2012. 
CARTA DA 19a ASSEMBLEIA XUKURU DO ORORUBÁ. Território Xukuru, Pesqueira (PE), Aldeia Pedra D'Água, 19 de maio de 2019. Disponível em: https://www.revistacontinente.com.br/secoes/extra/carta-da-19--da-assembleia-xukurudo-ororuba. Acesso em: 1 nov. 2019.

CARTA DA CASA DE SEMENTES. Território Xukuru, Pesqueira (PE), 07 de junho de 2019. CIMI. Estado brasileiro é condenado pela corte interamericana por violar direitos indígenas. Disponível em: https://cimi.org.br/2018/03/estado-brasileiro-econdenado-pela-corte-interamericana-por-violar-direitos-indigenas/. Acesso em: 05 ago. 2018.

FIALHO, Vânia; NEVES, Rita de C. Maria; FIGUEIROA, Mariana C. Leão. (Orgs) "Plantaram" Xicão: Os Xukuru do Ororubá e a criminalização do direito ao território. Manaus: PNCSAUEA/UEA Edições, 2011.

LIMA, Clarissa de Paula Martins. Corpos abertos: sobre enfeites e objetos na Vila de Cimbres (T.I. Xukuru do Ororubá). Dissertação de Mestrado apresentada ao Programa de Pós-Graduação em Antropologia Social da Universidade Federal de São Carlos, São Paulo, 2013.

MENDOZA, Constantino Calderón. Obstáculos normativos que invisibilizam los conocimientos originários andinos en la educación superior agronómica. Chile: InterCambios, Año 11, Número 124, Noviembre, 2011.

RIBEIRO, Berta G. O índio na cultura brasileira. Pequena Enciclopédia da Cultura Brasileira. Rio de Janeiro. UNIBRADE/UNESCO, 1987.

SILVA, Célio da. A volta da Asa Branca: a influência da educação contextualizada na construção da identidade do Povo Xukuru de Ororubá (Pesqueira-PE). Monografia apresentada ao Curso de Especialização em Educação Contextualizada para Convivência com o Semiárido Brasileiro da Universidade Federal de Campina Grande/Centro de Desenvolvimento Sustentável do Semiárido - PB. Sumé - PB, 2011.

VICK, Mariana. O que são terras indígenas. E qual a autonomia de seus ocupantes. Disponível em: https://www.nexojornal.com.br/expresso/2019/01/11/O-ques\%C3\%A3o-terras-ind\%C3\%ADgenas.-E-qual-a-autonomia-de-seus-ocupantes. Acesso em: 03 jun. 2019 